\title{
Estimativa de índices de conforto térmico por meio do uso de transecto móvel em Sorriso/MT
}

\author{
Mauro Sergio FRANÇA ${ }^{1}$ \\ ${ }^{1}$ Instituto Federal de Mato Grosso, Cuiabá, MT, Brasil \\ E-mail:mauroscottie@gmail.com
}

Recebido em outubro/2017; Aceito em agosto/2018.

\begin{abstract}
RESUMO: O objetivo deste estudo foi estimar níveis de conforto térmico no centro da cidade de Sorriso/MT, durante as estações seca e chuvosa. Para isso foi utilizado à metodologia do transecto móvel no período noturno que avaliou dois índices de conforto: o Índice de Temperatura e Umidade (ITU) e o Índice de Desconforto Humano (IDH). Os resultados obtidos mostraram que na estação seca ambos os índices tendem ao desconforto para o período, enquanto na estação chuvosa os mesmos apresentaram melhores condições de conforto. A temperatura exerceu a maior correlação com os índices e a maior determinação com os valores do IDH. Concluiu-se que o método adotado conseguiu identificar os níveis de conforto térmico, o que pode contribuir com futuras ações mitigadoras dessa problemática na área investigada.
\end{abstract}

Palavras-chave: urbanização, clima urbano, qualidade de vida.

\section{Estimate of the thermal comfort index by use of mobile transect in the Sorriso city/MT}

\begin{abstract}
The objective of this study was to estimate levels of thermal comfort in the city center of Sorriso/MT, during the dry and rainy seasons. For this, we used the mobile transect methodology in the night period that evaluated two comfort indexes: the Temperature and Humidity Index (TUI) and the Human Discomfort Index (HDI). The results showed that in the dry season both indices tend to discomfort for the period, while in the rainy season they presented better comfort conditions. The temperature had the highest correlation with the indices and the highest determination with the HDI values. It was concluded that the adopted method was able to identify the levels of thermal comfort, which may contribute to future mitigating actions of this problem in the researched area.
\end{abstract}

Keywords: urbanization, urban climate, quality of life.

\section{INTRODUÇÃO}

As modificações na superfície terrestre decorrentes da urbanização provocam diversos problemas ambientais, como a potencialização das enchentes e inundações devido à retirada da cobertura vegetal e impermeabilização do solo, os deslizamentos de encostas por conta da ocupação desordenada e do desmatamento das vertentes, a poluição dos solos, rios e corpos freáticos decorrente da má destinação dos resíduos sólidos, a poluição atmosférica resultante da circulação de veículos e do lançamento de gases industriais(CARDOSO; AMORIM, 2014; LUZ; RODRIGUES, 2014; ANDRADE et al., 2016). As alterações na atmosfera próxima da superfície aumentam a temperatura do ar, intensificam as chuvas, diminuem a umidade relativa e alteram a velocidade e direção dos ventos, criando assim um novo clima local (PORANGABA et al., 2017).

No Brasil, essa temática passou a ser investigada no trabalho desenvolvido por Monteiro (1976), que foi considerado o pioneiro no estudo do clima urbano. Nesse estudo o autor utilizou do conceito de ritmo proposto por Sorre em1934: "o clima é a série de estados atmosféricos acima de um lugar em sua sucessão habitual". O estado de São Paulo foi a principal área desse estudo, sendo o exemplo mais bem estudado a cidade de São Paulo, cuja temperatura média, em 1920 , era de $17,7^{\circ} \mathrm{C}$ e no início do século XXI estava em torno de $19^{\circ} \mathrm{C}$ (CONTI; FURLAN, 2001).
Em Mato Grosso os estudos de clima urbano tiveram o pioneirismo com as pesquisas de Maitelli et al. (1991), Maitelli (1994) ambos na capital, Cuiabá. Esses estudos constataram com medidas fixas e móveis a existência de ilhas de calor urbanas (ICU), todavia não objetivaram estimar índices de conforto térmico para Cuiabá.

As pesquisas sobre a temática conforto térmico no cenário nacional através de índices de conforto são recentes e buscam subsidiar políticas públicas de planejamento e gestão do espaço urbano, com ênfase na implantação e/ou ampliação da arborização urbana, áreas verdes e manutenção dos quintais urbanos(SOUZA; NERY, 2012; LOBATO et al., 2016; FANTE et al., 2017).

O conforto térmico consiste na sensação de neutralidade que um indivíduo mantém com o meio ao seu redor, ou seja, não existe a necessidade de mais calor ou frio para melhorar as condições ambientais naquele local. Desse modo, uma pessoa está confortável com relação a um acontecimento ou fenômeno quando pode observá-lo ou senti-lo sem preocupação ou incômodo (CORBELLA; YANNAS, 2003). Todavia nem sempre essas condições são encontradas pelo extenso território brasileiro.

Nesse aspecto por exemplo, nas cidades cujo uso e ocupação do solo apresentam na maioria das vezes, excessiva pavimentação e edificação e consequentemente supressão das áreas verdes na região central, pode-se verificar que o calor 
cada vez mais intenso nesses locais afetam o conforto e o desempenho dos seus ocupantes. Geralmente essas características arquitetônicas implicam na formação de ICU e desconforto térmico (SANTOS et al., 2013).

Costa; Franco (2013) explicaram que as ilhas de calor são anomalias térmicas caracterizadas pela elevação de temperatura em determinadas áreas e podem ser observadas em várias escalas, sendo que as mesmas ocorrem em locais com excessiva quantidade de construções e baixa concentração de áreas verdes onde a temperatura é mais elevada que áreas vizinhas não urbanizadas.

Frota; Schiffer (2003) afirmam que o desconforto térmico é uma das maiores reclamações dentre os fatores que compõem o conforto ambiental. O calor excessivo provoca efeitos sobre o indivíduo, deixando-o cansado, reduzindo sua atenção e aumentando as tendências em incorrer em erros ou acidentes.

Nesse caso, para identificar as condições de conforto e desconforto térmico surgiram diversas metodologias, sendo uma delas a do transecto móvel, que tem demonstrado boa resposta na análise da interação atmosfera-biosfera e suas relações com o ambiente construído (AMORIM et al., 2009; MARTINI et al., 2015).

Além disso, a padronização dos instrumentos de coleta de dados passou a ser fundamental para a qualidade dos estudos microclimáticos como destacado no trabalho de Valin Jr et al. (2016), onde os autores ressaltaram a importância deque muitos sensores, abrigos e sistemas alternativos são desenvolvidos, baseados na experiência e criatividade dos pesquisadores.

Diante disso, esta pesquisa objetivou estimar dois índices de conforto térmico na área central de Sorriso/MT com base na metodologia do transecto móvel, durante as estações seca e chuvosa.

\section{MATERIAL E MÉTODOS}

A pesquisa foi realizada na área central da cidade de Sorriso/MT entre as coordenadas $12^{\circ} 32^{\prime} 30^{\prime \prime}$ S e $55^{\circ} 42^{\prime} 29^{\prime}$ ' $\mathrm{W}$, com altitude média de $350 \mathrm{~m}$, com relevo predominantemente plano da Chapada dos Parecis, localizado na bacia do Teles Pires. O clima é "Aw" na classificação de Köppen, com quatro meses de seca (maio a agosto), com temperatura média anual de $24^{\circ} \mathrm{C}$ e chuva anual superior a 2.000 mm (FRANÇA; GOMES, 2014).

A cidade está situada na região médio-norte do estado de Mato Grosso, no km 742 ao longo da rodovia federal BR 163 (Cuiabá-Santarém) a cerca de $400 \mathrm{~km}$ da capital, Cuiabá (FERREIRA, 2001). A população estimada em 2017 era de 85.223 habitantes (IBGE, 2017). O percurso percorrido foi de $5,2 \mathrm{~km}$ (Figura 1), com início às $20 \mathrm{~h}$ e duração média de 25 minutos. Na estação chuvosa o início da coleta ocorreu a partir das 21 h devido ao horário de verão.

A metodologia adotada foi a do transecto móvel conforme proposto por Maciel et al (2011), Franco et al (2013) e Santos (2013), no qual foi utilizado um veículo automotor, de propriedade particular, cuja velocidade de deslocamento média foi de $10 \mathrm{~km} / \mathrm{h}$, sendo acoplado um abrigo termométrico portátil artesanal confeccionado de tubos de PVC (VALIN JR et al, 2016) instalado sob o teto do veículo a $2 \mathrm{~m}$ do solo (Figura 2 ).

A instrumentação contou com uma unidade Datalogger GK_V02 com GPS (Módulo GY-GPS6MV2); um sensor de umidade relativa e temperatura do ar (AM2302), gradiente de temperatura entre -40 a $80^{\circ} \mathrm{C}$, acurácia de $\pm 0,5^{\circ} \mathrm{C}$, gradiente de umidade relativa de 0 a $100 \%$, acurácia de $2-5 \%$, com frequência de uma leitura a cada 6 segundos; um módulo adaptador para cartão de memória FAT32 com 10G, com arquivo em texto ASCII, com campos separados por vírgula (Figura 3); uma bateria externa de 12V.

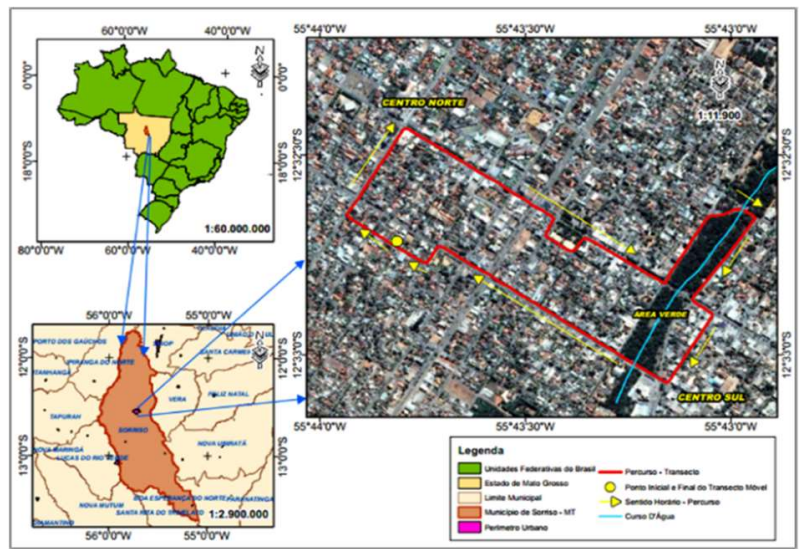

Figura 1: Localização da área de estudo na região central da cidade de Sorriso, Mato Grosso, Brasil. Elaboração: Lidiane Maria de Morais Costa

Figure 1: Location of the study area in the central region of the city of Sorriso, Mato Grosso, Brazil. Produced by: Lidiane Maria de Morais Costa

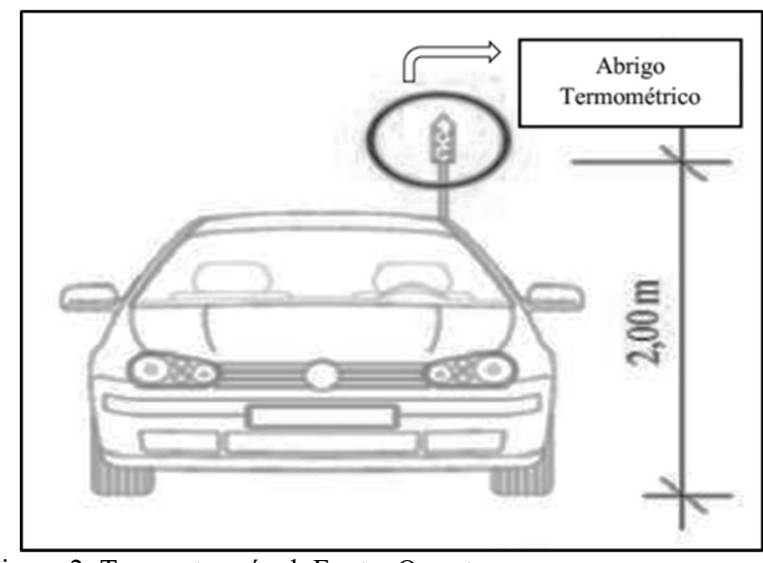

Figura 2: Transecto móvel. Fonte: Os autores

Figure 2: Mobile transecto. Source: Authors

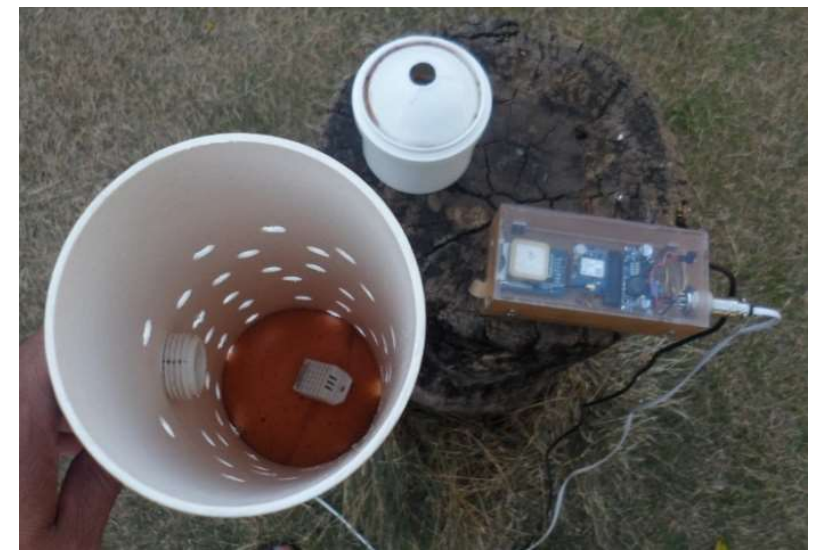

Figura 3: Abrigo termométrico, sensor e datalloger. Fonte: Os autores

Figure 3: Thermometric shelter, sensor and datalogger. Source: Authors 
Essa instrumentação foi desenvolvida no Laboratório de Instrumentação do Programa de Pós-Graduação em Física Ambiental da Universidade Federal de Mato Grosso (UFMT).

A escolha do trajeto levou em considerou o polígono da região central delimitado por suas principais avenidas (Tancredo Neves e Natalino João Brescansin) e uma extensa área verde que separa o centro norte e sul (Figura 4). Através desse polígono foi elaborado um buffer com a distribuição dos percentuais das classes de uso do solo.

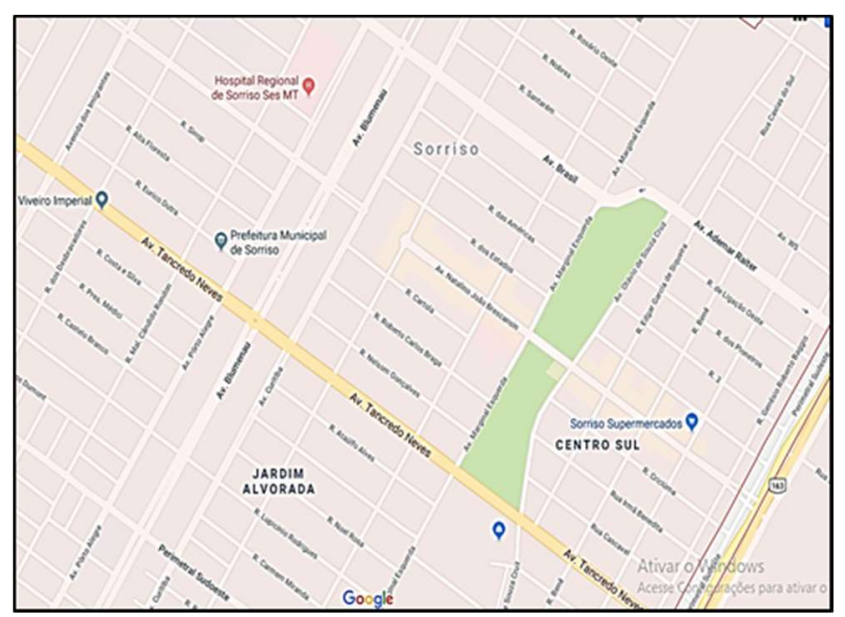

Figura 4: Principais avenidas da região central. Fonte: Google maps, 2018.

Figure 4: Main avenues of the central region. Source: Google Maps, 2018

O horário adotado (20h) é o recomendado pela Organização Mundial de Meteorologia (OMM) para o período noturno adaptado ao fuso horário local ( $-4 \mathrm{~h}$ UTC). Segundo Maitelli (1994) este horário é o mais apropriado para identificar possíveis ilhas de calor urbanas e evidenciar a contribuição dos diferentes usos e ocupação do solo nas variações microclimáticas do espaço urbano.

Os dados coletados foram medidos em cinco episódios da estação seca de 2015 (dias 17, 20, 22, 25, 31 de agosto) e cinco na estação chuvosa de 2016 (dias 05, 07, 08, 11, 19 de janeiro). Esses dias foram selecionados por serem representativos para a sazonalidade regional e terem apresentados condições favoráveis para a coleta, com noites de céu claro e ventos fracos. O registro totalizou 1248 dados na estação seca e 1243 na chuvosa.

Os dados foram tabulados em TXT - bloco de notas e exportados para planilhas CSV do Microsoft Excel 2013, onde foi feita a análise estatística, sendo calculado os coeficientes de correlação de Pearson (r), de determinação $\left(\mathrm{r}^{2}\right)$ e o erro padrão $(\delta)$. Foram utilizados dois índices de conforto térmico para o estudo. $\mathrm{O}$ primeiro foi o Índice de Temperatura e Umidade (ITU), descrito na Equação 1 (NÓBREGA; LEMOS, 2011):

$$
I I T U=0,8 * T_{a}+\frac{U R * T_{a}}{500}
$$

(Equação 1)

em que, $T a\left({ }^{\circ} \mathrm{C}\right)$ é a temperatura do ar, $U R(\%)$ é a umidade relativa do ar.

Esse índice está classificado em três níveis de conforto térmico segundo a Tabela 1:
Tabela 1. Critérios da classificação do Índice de Temperatura e Umidade

Table 1. Criteria for the classification of the Temperature and Humidity Index

\begin{tabular}{cc}
\hline Níveis de conforto & Sensação de Conforto \\
\hline $21<\mathrm{ITU}<24$ & Confortável \\
\hline $24<\mathrm{ITU}<26$ & Levemente desconfortável \\
\hline ITU $>26$ & Extremamente desconfortável \\
\hline
\end{tabular}

Para Barbirato (2007) e Lobato et al. (2016) esse índice permite uma boa quantificação o estresse térmico em ambientes urbanos e é de fácil praticidade de aplicação em ambientes abertos, dependendo apenas de duas variáveis ambientais, a temperatura e umidade.

O outro índice utilizado foi o Índice de Desconforto de Humano (IDH), Equação 2, proposto por ONO; KAWAMURA (1991). Os autores utilizaram esse índice em pesquisas na Ásia das Monções, sendo que o mesmo apresentou bom aproveitamento para áreas de climas quentes e úmidos.

$$
\mathrm{IDH}=0,99 * \mathrm{Ta}+0,36 * \text { To }+41,5
$$

(Equação 2)

em que:Ta $\left({ }^{\circ} \mathrm{C}\right)$ é a temperatura do ar e To $\left({ }^{\circ} \mathrm{C}\right)$ é a temperatura do ponto de orvalho.

A temperatura de orvalho não foi medida diretamente no estudo, mas foi estimada pela Equação 3 (ANOVA AGROTECNOLOGIA, 2011).

$$
\begin{array}{r}
\text { To }=\mathrm{Ta}-(14,55+0,114 * \mathrm{Ta}) * 1-(0,01 * \mathrm{UR})- \\
(2,5+0,007 * \mathrm{Ta}) * 1-(0,01 * \mathrm{UR})^{3}-(15,9+0,117 * \\
\text { Ta }) * 1-(0,01 * \mathrm{UR})^{14}(\text { Equação } 3)
\end{array}
$$

em que:Ta $\left({ }^{\circ} \mathrm{C}\right)$ é a temperatura do ar e $U R(\%)$ é a umidade relativa do ar.

As faixas de sensação de desconforto térmico estão descritas na Tabela 2 .

Tabela 2. Classificação do Índice de Desconforto Humano

Table 2. Classification of Human Discomfort Index

\begin{tabular}{cc}
\hline Intervalo do IDH & Efeitos \\
\hline IDH $>80$ & Estresse devido ao calor \\
\hline $75>$ IDH $>80$ & Desconfortável devido ao calor \\
\hline $60>$ IDH $>75$ & Confortável \\
\hline $55>$ IDH $>60$ & Desconfortável devido ao frio \\
\hline IDH $<55$ & Estresse devido ao frio \\
\hline
\end{tabular}

\section{RESULTADOS}

A caracterização das classes de uso do solo no entorno do percurso (buffer) mostrou predomínio de superfície impermeabilizada em detrimento à área verde (Tabela 3).

Os resultados na análise estatística descritiva da temperatura média $\left(\mathrm{T}_{\mathrm{d}}\right)$, máxima $\left(\mathrm{T}_{\mathrm{x}}\right)$ e mínima $\left(\mathrm{T}_{\mathrm{m}}\right)$ do ar e da umidade relativa (UR), bem como os valores estimados do ITU, do IDH e do desvio padrão (d) foram descritos na Tabela 4.

Percebeu-se que as $T_{d}, T_{x}$ e $T_{m}$ foram superiores, seguido da UR baixa na estação seca, o que representou maior desconforto, contudo não foram constatados níveis de extremo desconforto na amostragem devido essa análise ter ocorrido no período de arrefecimento da atmosfera. 
Notou-se na estimativa que os valores médios do ITU tanto na estação chuvosa e quanto na seca foram próximos, representando condições levemente desconfortáveis. Essa evidência ocorreu devido ao transecto abranger uma área predominantemente impermeabilizada e pavimentada (Tabela 3) que, aliado ao calor antropogênico liberado na área central, facilitou o armazenamento de calor sensível nos materiais urbanos e posteriormente a sua dissipação ao longo da noite.

Com relação ao IDH, os valores médios estimados de IDH foram confortáveis para a estação chuvosa. Essa evidência decorreu do aumento da chuva para o período que diretamente elevou as taxas de UR e proporcionou uma amenização da temperatura do ar e o equilíbrio desta com a temperatura de orvalho ao longo do dia. Além disso, a nebulosidade, típica para o período, dificultou a incidência da radiação direta e difusa e, consequentemente representou a redução do aquecimento da superfície urbanizada.

Os coeficientes de correlação de Pearson (r), de determinação $\left(\mathrm{r}^{2}\right)$ e o erro padrão $(\delta)$ durante as estações, conforme a Tabela 5. Foram criados dois modelos para relacionar os dados meteorológicos (variáveis independentes) e os índices estimados (variáveis dependentes).

Percebeu-se forte correlação e determinação estatística entre as variáveis nos modelos ( $\rho$-value $<0,05)$, sendo que os valores estimados de conforto térmico foram condizentes para aplicação em ambientes urbanizados conforme a metodologia adotada.

Tabela 3. Classes de uso do solo na área de estudo.

Table 3. Classes of land use in the study area.

\begin{tabular}{ccc}
\hline Classes de usos & Área ocupada $\left(\mathrm{m}^{2}\right)$ & Distribuição $(\%)$ \\
\hline Área construída & $1.311 .995,00$ & 71,45 \\
Pavimentação asfáltica & $352.000,32$ & 19,17 \\
Área verde & $172.177,53$ & 9,38 \\
\hline Total da área do buffer & $1.836 .172,85$ & 100 \\
\hline
\end{tabular}

Tabela 4. Valores médios, máximos, mínimos e desvio padrão das variáveis e índices.

Table 4. Variables and indices: mean, maximum, minimum and standard deviation

\begin{tabular}{c|c|c|c|c|c|c|c|c}
\hline & \multicolumn{4}{|c|}{ Estação Seca } & \multicolumn{4}{c}{ Estação chuvosa } \\
\hline Var. & $\mathrm{T}_{\mathrm{d}}$ & $\mathrm{T}_{\mathrm{x}}$ & $\mathrm{T}_{\mathrm{m}}$ & $\partial$ & $\mathrm{T}_{\mathrm{d}}$ & $\mathrm{T}_{\mathrm{x}}$ & $\mathrm{T}_{\mathrm{m}}$ & $\partial$ \\
\hline T & 28,2 & 30,0 & 25,9 & 0,9 & 25,2 & 26,5 & 24,0 & 0,7 \\
\hline UR & 42,9 & 51,2 & 37,0 & 3,2 & 89,5 & 99,9 & 83,8 & 3,3 \\
\hline ITU & 25,0 & 26,3 & 23,3 & 0,7 & 24,7 & 25,7 & 23,8 & 0,5 \\
\hline IDH & 79,0 & 81,4 & 76,5 & 1,2 & 75,6 & 77,1 & 74,2 & 0,8 \\
\hline
\end{tabular}

Tabela 5. Resultados dos modelos estimados entre os índices e as variáveis

Table 5. Results of estimated models between indices and variables

\begin{tabular}{c|c|c|c|c|c|c}
\hline & \multicolumn{3}{|c|}{ Estação Seca } & \multicolumn{3}{c}{ Estação Chuvosa } \\
\hline Modelos & $\mathrm{R}$ & $\mathrm{r}^{2}$ & $\delta$ & $\mathrm{r}$ & $\mathrm{r}^{2}$ & $\delta$ \\
\hline ITU/T e UR & 0,99 & 0,99 & 0,02 & 0,99 & 0,99 & 0,02 \\
\hline IDH/T e UR & 0,97 & 0,95 & 0,23 & 0,98 & 0,96 & 0,15 \\
\hline
\end{tabular}

\section{DISCUSSÃO}

Alguns estudos sobre o microclima urbano e suas relações com áreas verdes basearam-se em observações com pontos fixos e móveis e utilizaram os dias representativos para a análise dos resultados observados (GHENO et al., 2012; SILVA; ALMEIDA 2012; ANJOS et al., 2013).

Estudo realizado por Cessa (2017) avaliou o conforto térmico em duas áreas verdes na cidade de Sorriso/MT, a área verde central e a do Parque Ecológico Municipal pelo
Índice Desconforto Térmico (IDT). O estudo analisou as condições microclimáticas em dois dias típicos da estação quente-seca (17 e 20/09) e verificou que o conforto térmico nessas áreas verdes ocorreu entre a meia-noite e às 08:30 h, sendo que das $15 \mathrm{~h}$ até a meia noite as condições foram de conforto térmico parcial. Esses resultados foram identificados no transecto na referida estação no qual os dois índices analisados foram de levemente desconfortável a desconfortável pelo calor.

Martini et al. (2017) avaliou a variação diária do microclima urbano de Curitiba/PR em diferentes tipologias de floresta urbana durante dois dias representativos do verão e do inverno em 15 pontos amostrais e percebeu que em áreas com predominância de vegetação remanescente de floresta a temperatura e a umidade apresentaram os valores mais confortáveis, sendo que essas diferenças foram mais perceptíveis entre às 13 e $17 \mathrm{~h}$. No período noturno o estudo identificou que em áreas verdes antigas, semelhantes ao do transecto, registrou-se menores valores de umidade relativa e os maiores de temperatura, similar ao obtido neste estudo.

Silva et al. (2015) estudou a influência da vegetação no microclima na área urbana de Vitória/ES em um único dia do verão (14/01) em quatro pontos distribuídos no Parque Pedra da Cebola e suas imediações e verificou que o ponto localizado dentro do parque foi aquele que apresentou um ambiente climaticamente mais agradável, o que foi justificado pela concentração de espécies vegetais que reduziu a temperatura em $3^{\circ} \mathrm{C}$ se comparado aos outros pontos no intervalo da medição (entre 12 e $15 \mathrm{~h}$ ).

Moura et al. (2013) analisou o clima urbano de Cuiabá/MT e constatou que a influência do fluxo de veículos automotores nos ganhos de calor no meio é evidente, já que áreas com menor circulação de automóveis apresentaram climas mais agradáveis às áreas com as mesmas características de ocupação do solo, mas com menor fluxo de veículos, e consequentemente menor calor antropogênico. Essa constatação foi verificada neste estudo, visto que, o percurso abrangeu a área central onde durante o início do período noturno ocorreu intenso fluxo de veículos devido o fim do expediente comercial.

O trabalho de Rocha e Fialho (2010) comparando a região central de Viçosa/MG e o campus da Universidade Federal de Viçosa, ambos situados no mesmo fundo de vale, mostrou que a região central apresentou dificuldade em dissipar a energia que vem sendo acumulada ao longo do dia, sobretudo, do processo de urbanização e do ritmo das atividades antrópicas que se expressam no local.

\section{CONCLUSÕES}

Conclui-se que a metodologia do transecto móvel noturno consegue identificar na região central de Sorriso situações de desconforto na estação seca e conforto na estação chuvosa com os índices analisados. Esse fato deve-se ao adensamento urbano e a supressão da cobertura vegetal urbana.

$\mathrm{O}$ estudo recomenda aos gestores do planejamento urbano a discussão sobre a importância de se estabelecer critérios para o uso e a ocupação do solo, incentivando a utilização de materiais que retenham menor quantidade de energia durante o dia e dissipem de forma mais acelerada durante a noite, contribuindo assim para melhorias nas condições de conforto térmico local. 
Além disso, para melhorar as condições ambientais naquele ambiente torna-se indispensável a manutenção e, se possível, a ampliação das áreas verdes e arborização urbana que com o sombreamento e a evapotranspiração proporcionarão condições atmosféricas mais favoráveis ao conforto térmico.

\section{AGRADECIMENTOS}

Esta pesquisa contou com apoio financeiro do Conselho Nacional de Desenvolvimento Científico e Tecnológico (CNPq) através de bolsa de estudos para o primeiro autor.

\section{REFERÊNCIAS}

AMORIM, M. C. C. T.; SANT'ANNA NETO, J. L.; DUBREUIL, V. Estrutura térmica identificada por transectos móveis e canal termal do Landsat 7 EM cidade tropical. Revista Geografia Norte Grande, Santiago, n. 43, p. 65-80, 2009. DOI: http://dx.doi.org/10.4067/S0718-34022009000200004

ANDRADE, T. C. Q.; NERY, J. M. F. G.; SOUZA, S. H. M.; PITOMBO, C. S.; FREIRE, T. M. M.; KATZSCHNER, L. Medição do conforto térmico em áreas públicas urbanas de Salvador - BA e calibração do índice de conforto PET usando a técnica árvore de decisão. Revista Eletrônica de Gestão e Tecnologias Ambientais/GESTA, Salvador, v. 4, n. 2, p. 278-296, 2016. DOI: http://dx.doi.org/10.9771/gesta.v4i2.16821

ANJOS, M. W. B.; GANHO, N.; ARAÚJO, H. M. Uma análise dos contrastes topoclimáticos no espaço urbano e periurbano de Aracajú/SE: Os campos térmicos e higrotérmicos. Revista Brasileira de Climatologia, Presidente Prudente, v. 13, p. 298-318, jul/dez 2013. DOI: http://dx.doi.org/10.5380/abclima.v13i0.31090

ANOVA AGROTECNOLOGIA. Clima online: como calculamos 0 ponto de orvalho. ART 11/2011. Disponível em $<$ http://www.climaonline.com.br/art_pdf/calc_po.pdf $>$. Acesso em: 20 de maio de 2017.

BARBIRATO, G. M.; SOUZA, L. C. L.; TORRES, S. C. Clima e Cidade: a Abordagem Climática como Subsídio para Estudos Urbanos. Maceió/AL: EDUFAL, 2007, 154 p.

CARDOSO, R. S.; AMORIM, M. C. C. T. Características do clima urbano em Presidente Prudente/SP a partir de dados de temperatura e umidade relativa do ar e técnicas de sensoriamento remoto. Revista do Departamento de Geografia - USP, São Paulo, v. 28, p. 39-64, 2014 DOI: https://doi.org/10.11606/rdg.v28i0.494

CESSA, R. M. A. Conforto térmico em áreas verdes na cidade de Sorriso - MT. Revista da Sociedade Brasileira de Arborização Urbana, Piracicaba, v. 12, n. 1, p. 17-30, 2017.

CONTI, J. B.; FURLAN, S. A. Geoecologia: O Clima, os Solos e a Biota. In: ROSS, J. L. S. (Org.). Geografia do Brasil. 4 ed. São Paulo: Editora da Universidade de São Paulo, 2001. p. 67-208.

CORBELlA, O.; YANNAS, S. Em busca de uma arquitetura sustentável para os trópicos - um conforto ambiental. 1. ed. Rio de Janeiro: Revan, 2003. 288 p.

COSTA, A. S.; FRANCO, I. M. Aplicação de imagens termográficas para caracterização do calor urbano. Revista de Ciências da Amazônia, Macapá, n. 1, v. 2, p. 18-26, 2013.Disponível em:
http://www.periodicosueap.com.br/index.php/RCA/article /view/75/pdf_2 Acesso em setembro de 2014.

FANTE, K. P.; DUBREUIL, V.; SANT'ANNA NETO, J. L. Avaliação comparativa entre metodologias de identificação de situações de conforto térmico humano aplicado ao contexto tropical. Revista Brasileira de Climatologia, Presidente Prudente, v. 21, p. 588-612, jul/dez.

2017.

DOI: http://dx.doi.org/10.5380/abclima.v21i0.53839

FERREIRA, J. C. V. Mato Grosso e seus municípios. Cuiabá: Secretaria de Estado de Educação, 2001.

FRANCO, F. M.; NOGUEIRA, M. C. A.; PINTO-JÚNIOR, O. B.; BIUDES, M. S.; NOGUEIRA, J. S. Traçado urbano e sua influência no microclima: um estudo de caso em centro histórico. Revista Eletrônica em Gestão, Educação e Tecnologia Ambiental, Santa Maria, v. 9, n. 9, p. 1916-1931, fev. 2013. DOI: http://dx.doi.org/10.5902/223611707697

FRANÇA, M. S.; GOMES, E. S. Indícios de ilha de calor urbana em Sorriso/MT. Revista Monografias Ambientais - REMOA, Santa Maria, v. 14, n. 3, p.33663376, mai./ago. 2014. DOI: http://dx.doi.org/10.5902/2236130813401

FROTA, A. B.; SCHIFFER, S. R. Manual de conforto térmico: arquitetura e urbanismo. $7^{\mathrm{a}}$ ed. São Paulo: Stúdio Nobel, 2003.

GHENO, E. L.; FRANÇA, M. S.; MAITELLI, G. T. Variações microclimáticas na área urbana de Sinop, no final da estação chuvosa. Revista Educação, Cultura e Sociedade, Sinop, v. 2, n. 1, p. 139-153, jan./jul. de 2012.

GOOGLE MAPS. Disponível em: $<$ https://www.google.com.br/maps/place/Sorriso, $,+\mathrm{MT},+7$ 8890-000/@-12.5474465,-55.7619461,13z>. Acesso em 25 de março de 2018.

IBGE_Instituto BRASILEIRO DE GEOGRAFIA E ESTATÍSTICA. Estimativa Populacional 2017. Disponível em: $<$ http://cidades.ibge.gov.br/brasil/mt/sorriso/panorama Acesso em 31/10/2017.

LOBATO, G. J. M.; MARTORANO, L. G.; LUCAS, F. C. A.; TAVARES-MARTINS, A. C. C.; JARDIM, M. A. G. Condições térmico-hídricas e percepções de conforto ambiental em quintais urbanos de Abaetetuba, Pará, Brasil. Revista Ra'eGa, Curitiba, v. 38, p. 245-268, dez. 2016. DOI: http://dx.doi.org/10.5380/raega.v38i0.43705

LUZ, L. M.; RODRIGUES, J. E. C. Análise do índice de cobertura vegetal em áreas urbanas: estudo de caso da cidade de Belém - PA. Boletim da Amazônico de Geografia, Belém, n. 1, v. 1, p. 43-57, jan/jun. 2014. DOI: 7040/bag.n1v1p43-57

MACIEL, C. R; NOGUEIRA, M. C. J. A; NOGUEIRA, J. S. Cobertura do solo e sua influência na temperatura de microclimas urbanos na cidade de Cuiabá/MT. Caminhos de Geografia. Uberlândia, v. 12, n. 39, p.4057, set. 2011.

MAITELLI, G. T.; ZAMPARONI, C.A.G.P.; LOMBARDO, M.A. Ilha de calor em Cuiabá/MT: uma abordagem de clima urbano. Encontro Nacional de Estudos do Meio Ambiente, 3., 1991. Anais. Londrina: Universidade Estadual de Londrina, 1991. p. 561-571. 
MAITELLI, G. T. Uma abordagem tridimensional de clima urbano em área tropical continental: o exemplo de Cuiabá - MT. 1994. 204 p. Tese (Doutorado em Geografia) - Faculdade de Filosofia, Letras e Ciências Humanas da Universidade de São Paulo, São Paulo, 1994.

MARTINI, A.; BIONDI, D.; VIEZZER, J.; SILVA, D. A. O efeito microclimático do fragmento florestal existente no Parque Municipal do Barigui na cidade de Curitiba/PR Ciência e Natura, Santa Maria, v. 37, ed. esp., p. 125 131, 2015. http://dx.doi.org/10.5902/2179460X16227

MARTINI, A.; BIONDI, D.; BATISTA, A. C. Variação diária do microclima urbano em diferentes tipologias de floresta urbana. NATIVA, Sinop, v. 5, n. 5, p. 342-348, set./out. 2017. DOI: http://dx.doi.org/10.5935/23187670.v05n05a07

MONTEIRO, C. A. F. Teoria e clima urbano. Séries teses e monografias, n. 25. São Paulo: Instituto de Geografia da Universidade de São Paulo, 1976. 181 p.

MOURA, F. M. M.; OLIVEIRA, A. S.; NOGUEIRA, M. C. J. A.; MUSIS, C. R.; NOGUEIRA, J. S. Análise do clima urbano de Cuiabá/MT por meio de transectos móveis. In: XII Encontro Nacional e VIII Encontro Latinoamericano de conforto em ambiente construído ENCAC/ELACAC. Conforto \& Projetos: Cidades. Paranoá, v.11. p.45-53, Brasília, 2013.

NÓBREGA, R. S.; LEMOS, T. V. S. O microclima e o (des) conforto térmico em ambientes abertos na cidade de Recife. Revista de Geografia (UFPE), Recife, v. 28, n. 1, p. 93-109, 2011.

ONO, H. S. P.; KAWAMURA T. Sensible Climates in Monsoon Asia. International Journal of Biometeorology, Lisse, vol. 35, n. 1, p.39-47, 1991. DOI: https://doi.org/10.1007/BF01040962

PORANGABA, G. F. O.; TEIXEIRA, D. C. F.; AMORIM, M. C. C. T. Procedimentos metodológicos para análise das ilhas de calor em cidades de pequeno e médio porte. Revista Brasileira de Climatologia, Presidente Prudente, v. 21, p. 225-247, jul./dez. 2017. DOI: http://dx.doi.org/10.5380/abclima.v21i0.48832
ROCHA, V. M.; FIALHO, E. S. Uso da terra e suas implicações na variação termo-higrométrica ao longo de um transecto campo-cidade no município de Viçosa-MG. Revista de Ciências Humanas, v. 10, n. 1, p. 64-77, jan./jun. 2010.

SANTOS, F. M. M. Clima urbano de Cuiabá - MT - Brasil: ocupação do solo e suas influências. Revista Monografias Ambientais - REMOA, Santa Maria, v. 12, n. 12, p. 2749-2763, ago. 2013.

SANTOS, F. M. M.; NOGUEIRA, M. C. J. A.; DE MUSIS, C. R.; PINTO JUNIOR, O. B.; NOGUEIRA, J. S. Influência da ocupação do solo no clima urbano de Cuiabá, estado de Mato Grosso, Brasil. Brazilian Geographical Journal: Geosciencies and Humanities research medium, Ituiutaba, v. 4, n. 1, p. 100-121, jan./jun. 2013.

SILVA, V. P. R.; ALMEIDA, R. S. R. Estudo do clima urbano de Campina Grande, PB. Revista de Ciências da Vida, v. 32, n. 1, p. 31-44, jan./jun. 2012.

SILVA, B. A. S.; XAVIER, T. C.; ALVAREZ, C. E. A influência da vegetação no conforto térmico para a condição microclimática de Vitória (ES). Cidades Verdes, v. 3, n. 8, p. 1-15, 2015. DOI: http://dx.doi.org/10.17271/23178604382015980

SOUZA, D. M.; NERY, J. T. O conforto térmico na perspectiva da Climatologia Geográfica. Geografia (Londrina), Londrina, v. 21, n. 2, p. 65-83, maio/ago. 2012.

VALIN JUNIOR, M. O.; SANTOS, F. M. M.; RIBEIRO, K. F. A.; NOGUEIRA, M. C. J. A.; NOGUEIRA, J. S. Análise da relação entre abrigos meteorológicos alternativos para pontos fixos e o comportamento de variáveis termo-higrométricas. Revista Brasileira de Climatologia, Presidente Prudente, v. 18, jan./jun. 2016. DOI: http://dx.doi.org/10.5380/abclima.v18i0.45146 